\title{
Uji Tarik pada Timing Belt Mobil L300
}

\author{
Jusnita, Indra Saputra \\ Program Studi Teknik Otomotif Fakultas Teknik \\ Universitas Muhamadiyah Riau \\ Email : jusnita_ita@yahoo.co.id
}

\begin{abstract}
Abstrak
Fungsi timing belt pada mesin L300 adalah memindahkan daya dari motor ke crankshaft. Timing belt rentan mengalami kerusakan karena timing belt mengalami gesekan dengan pully. Ada beberapa penyebab kegagalan pada timing belt, seperti : tekanan kerja melebihi dari tekanan kerja timing belt yang diijinkan. Kelemahan rantai timing adalah bunyinya yang kasar sehinga membutuhkan perawatan yang maksimal. Tujuan dari penelitian ini adalah untuk mengetahui kekuatan tarik dari timing belt mobil diesel L 300 menggunakan alat uji tarik. Metode yang digunakan dalam penelitian ini adalah metode pengujian tarik menggunakan alat uji computer servo control material testing machine dengan panjang cekannya (Grif Length) $90 \mathrm{~mm}$ dengan membandingkan timing belt original dengan timing belt $K W 1$. Hasil penelitian untuk spesimen timing belt original merek Genuine Part nilai Mod $156180.34 \mathrm{~cm}^{2}$, max force $16147.2 \mathrm{kgf}, 0,2 \% \quad 79.27439 Y . S \mathrm{kgf} / \mathrm{cm}^{2}$, yield strength $79,27 \mathrm{kgf} / \mathrm{cm}^{2}$, tensile strength $104.75 \mathrm{kgf} / \mathrm{cm}^{2}$, elongation 6,71. Sedangkan untuk spesimen timing belt $\mathrm{KW} 1$ merek jibox didapat hasil pengujian nilai Mod $46722.70 \mathrm{~cm}^{2}$, max force $5843.2 \mathrm{kgf,0,2 \%} 27.48854 \mathrm{y.s} \mathrm{kgf} / \mathrm{cm}^{2}$, yield strength 11,21 kgf/ $\mathrm{cm}^{2}$, tensile strength $37,90 \mathrm{kgf} / \mathrm{cm}^{2}$, elongation 8,11. material timing belt L 300 merek Genuin Part mengalami putus/gagal terjadi pada tegangan (stres) 82 Mpa dengan regangan 0,01 (10\%). Sedangkan untuk material timing belt L 300 merek Jibox menglami putus/gagal pada tegangan 35 Mpa dengan regangan (7\%), maka dapat kesimpulan bahwa timing belt merk Genuine part mempunyai tegangan (stress) 83 Mpa lebih besar dibandingkan dengan material timing belt $K W 1$ merek Jibox $35 \mathrm{Mpa}$, sehingga selisih tegangan kedua material tersebut adalah 48 Mpa. Sedangkan untuk nilai regangannya (strength) pada timing belt merk Geniune Part adalah 0.01 (10\%). Dan untuk material timing belt KW 1 merk Jibox mempunyai regangan (strength) 0.07 (7\%). Maka selisih kedua regangan material timing belt tersebut adalah 0,03 (3\%).
\end{abstract}

Kata kunci : Timing Belt, Uji Tarik, Yield Strength, Tensile Strength, Elongation

\section{Pendahuluan}

Timing Belt adalah salah satu komponen yang berperan besar dalam menentukan kerja mesin, bekerja dengan cara memutar camshaft yang mengatur kapan saatnya katup membuka dan menutup agar selaras dengan naik. Jika timing belt putus saat kendarai diperjalanan, sudah pasti mobil mogok. Fungsi timing belt adalah untuk menghubungkan/memindahkan daya dari motor ke crankshaft dari crank shaft daya putar motor. Timing belt rentan mengalami kerusakan karena timing belt mengalami gesekan dengan pully, tegangan dan tempratur dari motor yang terus berputar. Ada beberapa faktor yang menyebabkan timing belt gagal seperti: tekanan kerja melebihi dari tekanan kerja timing belt yang diijinkan. Dilihat dari segi materialnya timing belt berbeda dengan timing chain, kalau timing belt terbuat dari bahan sabuk nylon sementara kalau timing chain berbentuk rantai sebagai tali penghubung. Keduanya baik timing belt maupun timing chain memutar kruk as dan kem. Perbedaan antara timing belt dengan timing chain, timing belt memiliki kelebihan diantaranya adalah lebih ringan, tidak berisik, lebih fleksibel, dapat digunakan pada mesin RPM tinggi dan tidak memerlukan pelumasan. Kelemahannya adalah kurang kuat, masa penggantian lebih cepat.

Jika timing belt pada mesin putus di saat mesin sedang bekerja, karena pembakaran bekerja dengan cepat, proses buka tutup klep pun berjalan sangat cepat, jadi kemungkinan besar saat timing belt putus kondisi klep sedang terbuka (menjorok masuk ke dalam ruang pembakaran). Akibatnya, piston pembakaran akan menabrak klep yang sedang terbuka tersebut. Akibatnya jelas sangat fatal, klep dan kepala piston yang beradu tersebut akan hancur. 
Jika hal ini sampai terjadi (timing belt putus), maka mobil akan mati total. Kalaupun mesin dipaksa untuk dihidupkan, maka akan mengakibatkan kerusakan yang lebih parah pada piston dan klep. Untuk memperbaikinya mesin harus dibongkar (turun mesin) piston dan klep kemungkinan besar harus diganti, dan jelas bukan masalah kecil karena posisi mereka ada didalam silinder pembakaran. Harganyapun relatif mahal untuk turun mesin. Maka untuk itu perlu penelitian untuk mengetahui kekuatan tarik mobil L 300.

\subsection{Tujuan Penelitian}

Tujuan penelitian ini adalah untuk mengetahui kekuatan tarik mobil L 300. Pengujian tarik banyak dilakukan untuk melengkapi informasi rancangan dasar kekuatan suatu bahan dan sebagai data pendukung bagi spesifikasi bahan.

Karena dengan pengujian tarik dapat diukur ketahanan suatu material terhadap gaya statis yang diberikan secara perlahan. Pengujian tarik ini merupakan salah satu pengujian yang penting untuk dilakukan, karena dengan pengujian ini dapat memberikan berbagai informasi mengenai tegangan pada suatu material timing belt.

\subsection{Tinjauan Pustaka}

Timing belt adalah sebuah komponen pada mobil yang berfungsi untuk menghubungkan putaran antara Askruk dengan noken as, sehingga terjadi putaran yang sinkron antara kedua komponen tersebut. Jika timing belt mengalami kerusakan atau retak, maka bisa mempengaruhi performa mobil, terlebih lagi jika timing belt yang rusak tersebut terjadi pada mobil L300 mitsubishi, pastinya akan sangat menganggu.

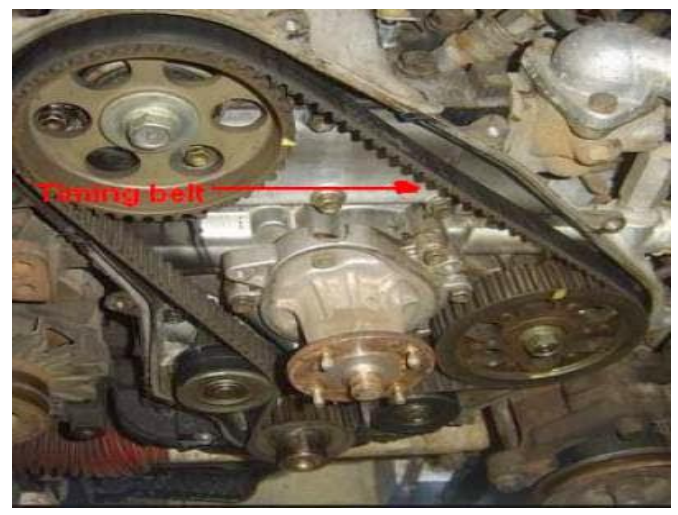

Gambar 1. Timing Belt

\subsection{Fungsi Timing Belt}

Fungsi utama timing belt adalah untuk mengerakkan katup dengan cara memutar Camshaft dan menggerakkan oil pump, menggerakkan water pump, dan menggerakkan fuel pump. Untuk menjaga kualitas timing belt, maka dalam penyimpanannya harus dihindari : Suhu yang tinggi (lebih dari $40^{\circ} \mathrm{C}$ ), terkena langsung sinar matahari, kelembaban yang tinggi (lebih dari 90\%), ditumpuk lebih dari standar, terjepit, tertekuk benda lain, terkontaminasi bahan kimia, oli, air dan lain-lain. Dan yang patut dihindari adalah memuntir, melipat, dan membuat gulungan kecil, karena hal di atas berakibat pada cacat awal seperti retak, sobek dan membuat kerusakan cord yang tidak terlihat.

Dari hasil pemeriksaan dan pengamatan secara visual terlihat dari putusnya timing belt mengalami tekanan yang berlebih hal ini bisa disebabkan oleh penyetelan tension timing belt yang tidak sesuai dengan standar, posisi sproket yang tidak center dengan timing belt sehingga menyebabkan timing belt slip kearah sisi sprocket. Sprocket yang ada dimotor berputar terus menerus dan timing belt sebagai penghantar daya ke sprocket yang ada pada crankshaft.

\subsection{Fungsi \& Struktur Binaan Belting}

Belting digunakan dalam sistem enjin, air-cond system, charging system, cooling system dan system power steering. Belting berfungsi menerima geseran yang tinggi daripada pemindahan putaran Crank shaft pully kepada pully-pully lain yang bersambung dengannya tanpa tergelincir mestilah boleh melentur mengikut lenggokan pully dan tahan kepada suhu kepanasan yang tinggi. Bahan asasnya terdiri daripada lembaran benang atau dawai yang digunakan sebagai menambahkan ketahanan belting.

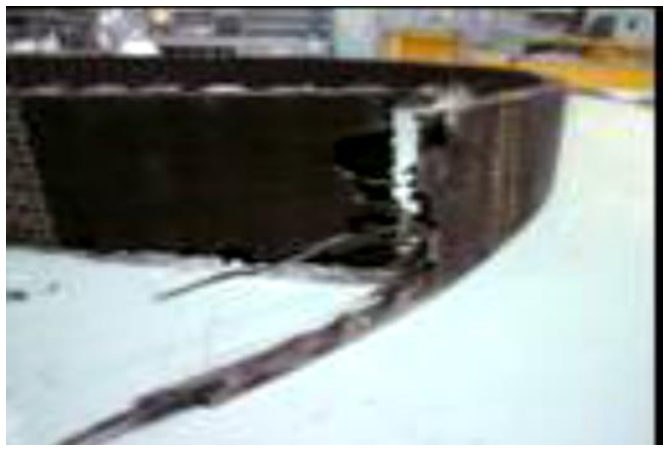

Gambar 2. Timing Belt Putus

Timing belt mempunyai umur pakai selama $40.000-60.000 \mathrm{~km}$. Timing belt sendiri letaknya

SURYA TEKNIKA Vol. 5 No. 2, Desember 2017: 69 - 73 
tertutup sehingga tidak dapat dilihat kasat mata dan tidak memiliki ciri-ciri apakah sudah dalam kondisi perlu penggantian part atau belum. Dan yang perlu diingat, Timing Belt itu tidak sama dengan Fan Belt (tali kipas) yang dapat dilihat dengan mudah oleh mata kita. Timing belt hanya menggandalkan record / catatan yang biasa ditulis tangan dan ditempel di cylinder head.

\subsection{Faktor-Faktor Penyebab Rusaknya Timming Belt}

Faktor -faktor lain yang menyebabkan terlalu tegangnya timing belt yaitu; 1) Kesalahan possi timing belt tehadap sproket yang tidak senter 2) Posisi sproket driver dan sproket driven tidak senter yang menyebabkan timing belt slip 3) Tegangan / tension yang diberikan pada timing belt tidak sesuai dengan standar timing belt yang digunakan 4) Vibrasi pada sproket motor yang terus berputar Selain itu ada beberapa faktor juga yang mempengaruhi putusnya timing belt 5) Kesalahan pengoprasian mesin oleh operator mesin 6) Cara pemasangan yang tidak memperhatikan posisi sproket yang tidak senter

Dari hasil uji propertise terlihat penurunan kinerja timing belt yang sangat signifikan yang disebabkan oleh faktor- faktor terlalu tegangnya timing belt yang menyebabkan timing belt gamp.

\subsection{Uji Tarik}

Uji tarik adalah suatu metode yang digunakan untuk menguji kekuatan suatu bahan/material dengan cara memberikan beban gaya yang sesumbu. Hasil yang didapatkan dari pengujian tarik sangat penting untuk rekayasa teknik dan desain produk karena menghasilkan data kekuatan material.

Pengujian uji tarik digunakan untuk mengukur ketahanan suatu material terhadap gaya statis yang diberikan secara lambat. Uji tarik banyak dilakukan untuk melengkapi informasi rancangan dasar kekuatan suatu bahan dan sebagai data pendukung bagi spesifikasi bahan. Nilai kekuatan dan elastisitas dari material uji dapat dilihat dari kurva uji tarik.

\subsection{Kekuatan Tarik}

Kekuatan yang biasanya ditentukan dari suatu hasil pengujian tarik adalah kuat luluh (Yield Strength) dan kuat tarik (Ultimate Tensile Strength). Kekuatan tarik atau kekuatan tarik maksimum (Ultimate Tensile Strength / UTS), adalah beban maksimum dibagi luas penampang lintang awal benda uji.

$$
S_{u}=\frac{P_{\text {maks }}}{A_{0}}
$$

di mana: $S_{u} \quad=$ Kuat tarik

$P_{\text {maks }}=$ Beban maksimum

$A_{0}=$ Luas penampang awal

\subsection{Kekuatan luluh (yield strength)}

Salah satu kekuatan yang biasanya diketahui dari suatu hasil pengujian tarik adalah kuat luluh (Yield Strength). Kekuatan luluh ( yield strength) merupakan titik yang menunjukan perubahan dari deformasi elastis ke deformasi plastis [Dieter, 1993].

Besar tegangan luluh dituliskan seperti pada persamaan 2.4, sebagai berikut.

$$
Y_{s}=\frac{P_{y}}{A_{0}}
$$

dimana ; Ys : Besarnya tegangan luluh $\left(\mathrm{kg} / \mathrm{mm}^{2}\right)$

Py : Besarnya beban di titik yield $(\mathrm{kg})$

Ao : Luas penampang awal benda uji $\left(\mathrm{mm}^{2}\right)$

\section{Methodologi}

\section{Hasil dan Pembahasan}

Hasil pengujian material timing belt mobil L 300 Diesel menggunakan alat uji tarik (computer servo control material testing machine) yang dilakukan dengan 6 speciment menggunakan alat uji tarik, maka diperoleh hasil pengujiannya sebagai berikut;

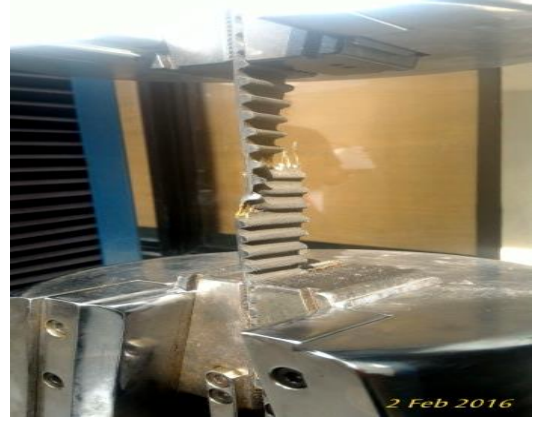

Gambar 3. Specimen pada alat uji 
Tabel 1.

Hasil uji tarik timing belt OR dan KW 1

\begin{tabular}{ccccccc}
\hline & \multicolumn{5}{c}{ Hasil Uji Tarik (kgf) } \\
\cline { 2 - 7 } $\begin{array}{c}\text { Speci } \\
\text { ment }\end{array}$ & $\begin{array}{c}\text { Mod } \\
\left(\mathrm{cm}^{2}\right)\end{array}$ & $\begin{array}{c}\text { Max. } \\
\text { force } \\
(\mathrm{kgf})\end{array}$ & $\begin{array}{c}0,2 \% \text { Y.S } \\
\left(\mathrm{kgf} / \mathrm{cm}^{2}\right)\end{array}$ & $\begin{array}{c}\text { Yield } \\
\text { strength } \\
\left(\mathrm{kgf} / \mathrm{cm}^{2}\right)\end{array}$ & $\begin{array}{c}\text { Tensil } \\
\text { strength } \\
\left(\mathrm{kgf} / \mathrm{cm}^{2}\right)\end{array}$ & $\begin{array}{c}\text { Elo } \\
\text { gati } \\
\text { on }\end{array}$ \\
\hline $\begin{array}{c}\text { Timing } \\
\text { belt OR }\end{array}$ & $\begin{array}{l}1561 \\
80.34\end{array}$ & 16147.2 & 79.27439 & 79.27 & 104.75 & 6.71 \\
\hline $\begin{array}{c}\text { Timing } \\
\text { belt }\end{array}$ & 4672 & 5843.2 & 27.48854 & 11.21 & 37.90 & 8.11 \\
KW 1 & 2.70 & & & & & \\
\hline
\end{tabular}

Spesiment material timing belt Genuine Part hasil pengujian uji tarik yang menggunakan alat servo maka untuk nilai elastisitas (Mod) adalah $156180.34 \mathrm{~cm}^{2}$, nilai maksimal gaya tariknya 16147 , $2 \mathrm{kgf} / \mathrm{cm}^{2}$, dan nilai dari kekuatan luluh (yield strength) $79.27 \mathrm{kgf} / \mathrm{cm}^{2}$. dan nilai kekuatan uji tarik dari tensile strength $104,75 \mathrm{kgf} / \mathrm{cm}^{2}$ Untuk speciment elogation pada pengujian tarik timing belt 6,71 .

Hasil pengujian tarik timing belt KW 1 merek jibox nilai kekuatan spesimen elastisitas ( $m o d)$ adalah $46722,70 \mathrm{~cm}^{2}$. Sedangkan nilai maksimal gaya tarik (Max.Force) 5843,2 kgf, dan nilai kekuatan luluh (Yield strength ) adalah $11,21 \mathrm{kgf} / \mathrm{cm}^{2}$. Nilai kekuatan tensile strength $37,90 \mathrm{kgf} / \mathrm{cm}^{2}$. Dan nilai dari spesimen Elogation pada pengujian tarik timing belt 8,1 .

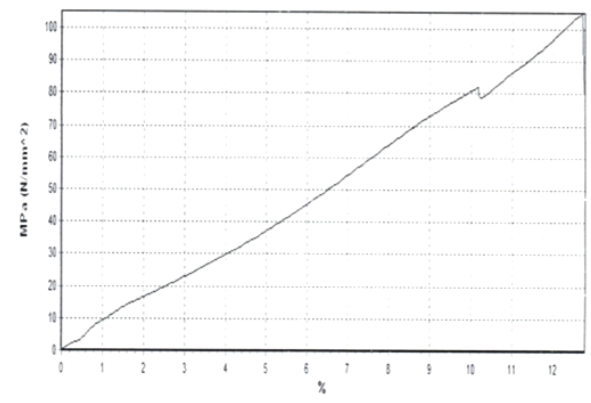

Gambar 4. Grafik Pengujian Tarik timing belt genuin pa

Material timing belt L 300 merek Genuin Part mengalami putus/gagal terjadi pada tegangan (stres) 82 Mpa dengan reganngan 0,01 (10\%). Sedangkan untuk material timing belt L 300 merek Jibox menglami putus/gagal pada tegangan $35 \mathrm{Mpa}$ dengan regangan $(7 \%)$.

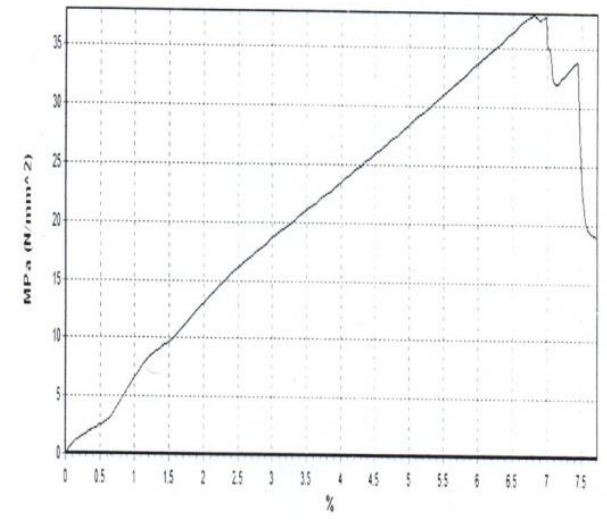

Gambar 5. Grafik kekuatan timing belt KW1

Maka dapat disimpulkan bahwa timing belt merk Genuine part mempunyai tegangan (stress) 83 Mpa lebih besar dibandingkan dengan material timing belt $\mathrm{KW} 1$ merek Jibox $35 \mathrm{Mpa}$, sehingga selisih tegangan kedua material tersebut adalah 48 Mpa. Sedangkan untuk nilai regangannya (strength) pada timing belt merk Geniune Part adalah 0.01 (10\%). Dan untuk material timing belt KW 1 merk Jibox mempunyai regangan (strength) 0.07 (7\%). Sehingga selisih kedua regangan material timing belt tersebut adalah $0,03(3 \%)$.

\section{Simpulan}

Dari penelitian ini dapat diambil kesimpulan bahwa nilai kekuatan timing belt KW 1 merk jibok lebih rendah dari pada timing belt merk Genuine Part. Salah satu penyebab seringnya terjadi putus pada timing belt KW 1 merk jibox adalah rendahnya nilai-nilai material.

\section{Daftar Pustaka}

[1] Manual book Draper Air Jet Machine 1986

[2] John Moubray, RCM II Reliability Center Maintenance,Second Edition

[3] ASTM Handbook, "Failure Analysis and Prevention"

[4] PowerGrip HTD Systems, Catalog 190/1982 UNIROYAL

[5] Efendi, Zainal, 2010. Jurnal Kekerasan Material Dengan Metode uji tarik,Fakultas Sains Dan Teknologi UA, Surabaya

[6] PT. SUKA FAJAR MITSHUBISHI, Pedoman Repara L300 : Mesin. TAM, Jakarta, 2004 
ISSN: 2354-6751

[7] PT. suka fajar mitsubishi, Step 2: Fuel System,TAM Training Center, Jakarta, 1995.

[8] L300, C. (2012). Pengertian timing belt. Retrieved September 4, 2012, from http://hinocatalog.blogspot.com/2012/08/.html 